\title{
Clube de programação e oficinas com o Scratch: um relato de experiência
}

\author{
Josiane Patrícia Rodrigues dos Santos Soares $^{1}$ \\ Rafael Garcia Cerci ${ }^{1}$ \\ Helio Henrique Lopes Costa Monte-Alto ${ }^{1}$
${ }^{1}$ Universidade Federal do Paraná (UFPR) - Setor Palotina - Palotina, PR - Brazil
\{josiane.patricia,rafael.cerci,heliohenrique\}@ufpr.br

\begin{abstract}
This work is being developed aiming to introduce computer programming, by means of the Scratch language, to middle-school students, as a way to develop their logical and computational thinking and incite them to have interest in Computer Science. The Scratch language allows students to improve the reasoning capabilities and mathematical knowledge that is essential to computer programming, playfully stimulating the interaction with the programming environment my means of blocks that remind LEGO toys. This study is being conducted by means of a programming club (or "Code Club") in partnership with a public school from Palotina-PR. Worskhops are also organized eventually. We present evidence that the workshops and the club arouse the students' interest for computer programming. Therefore, this study intends to evidence the effectiveness and feasability of introducing Computer Science for middle-school students and to evaluate Scratch in this context.
\end{abstract}

Resumo. Este projeto está sendo desenvolvido com o objetivo de introduzir a programação de computadores, por meio da linguagem Scratch, a alunos do Ensino Fundamental, como forma de desenvolver neles o raciocínio lógico e computacional e instigá-los ao interesse pela Computação. A linguagem possibilita ao aluno aprimorar o raciocínio e os conceitos matemáticos que norteiam a programação de computadores, visando estimular de maneira lúdica a interação por meio de blocos que remetem ao brinquedo de montar LEGO. O estudo está sendo realizado por meio de um clube de programação em parceria com um Colégio Estadual do município de Palotina-PR. Também são realizadas, eventualmente, oficinas de programação abertas à comunidade escolar. Apresentamos evidências de que as oficinas e o clube despertam o interesse dos alunos pela programação de computadores. Deste modo, este estudo pretende evidenciar a efetividade e viabilidade de introduzir a Ciência da Computação no Ensino Fundamental e avaliar o uso do Scratch neste contexto.

\section{Introdução}

É evidente nos cursos de Computação a dificuldade encontrada pelos alunos quando o assunto é programação, lógica, matemática ou algoritmo. E essa dificuldade também é um dos principais motivos da evasão em cursos da área de Computação. De fato, a programação é uma disciplina que, muitas vezes, apresenta resistência por parte dos alunos ingressantes em cursos superiores na área de Computação [Rebouças et al. 2010]. 
A aprendizagem de conceitos e métodos para a construção de programas de computador não é trivial, requerendo o uso de habilidades de alto nível e muito raciocínio abstrato [Castro et al. 2008]. O desenvolvimento de algoritmos é uma das competências mais difíceis de serem desenvolvidas, principalmente para aqueles que acabam de ingressar em cursos desta área [Júnior et al. 2005]. Várias pesquisas defendem, ainda, que conhecimentos sobre programação são importantes para estudantes que se interessam por outras áreas além da Ciência da Computação, desenvolvendo novas habilidades como o raciocínio lógico, resolução de problemas e pensamento algorítmico [Papert 1972, Wing 2006].

O ambiente de ensino Scratch foi criado com o propósito de introduzir a programação de maneira fácil e rápida para aqueles que não possuem nenhum tipo de experiência no assunto [Maloney et al. 2010]. A linguagem possibilita ao aluno o desenvolvimento do raciocínio lógico e conceitos matemáticos que norteiam a programação de computadores visando uma interação mais acessível por meio do desenvolvimento de programas através de blocos que remetem ao LEGO ${ }^{1}$.

Segundo estudos de educadores matemáticos, tais como [Papert 1972, Valente 1999], a construção significativa do conhecimento matemático inicia-se a partir do $6^{\circ}$ ano do Ensino Fundamental. Por isso, faz-se necessário estimular o desenvolvimento do pensamento lógico, operacional e relacional por volta dessa idade e série escolar.

Este artigo apresenta um relato de experiência do uso da linguagem Scratch com o objetivo de introduzir a programação de computadores a alunos do Ensino Fundamental, como forma de desenvolver neles o raciocínio lógico e computacional e instigá-los ao interesse pela Computação. A Seção 2 apresenta uma breve introdução ao Scratch. A Seção 3 apresenta a metodologia utilizada referente ao clube de programação e às oficinas realizadas. A Seção 4 apresenta alguns resultados e, enfim, são apresentadas algumas considerações finais.

\section{A Linguagem Scratch}

Scratch é uma linguagem gráfica de programação que foi desenvolvida pelo Instituto de Tecnologia de Massachusetts (do Inglês, Massachusetts Institute of Technology, MIT) com o objetivo de auxiliar na aprendizagem de programação, por meio da introdução de conceitos de operadores, estruturas de decisão, de repetição e variáveis, permitindo a aprendizagem de forma lúdica por alunos que não possuem nenhum conhecimento na área de programação.

A Linguagem Scratch tem como slogan a mensagem "imagine, programe, compartilhe", e foi concebido e desenvolvido como resposta ao problema do crescente distanciamento entre a evolução tecnológica no mundo e a fluência tecnológica dos cidadãos. É com este intuito que a linguagem e ambiente de programação gráfica do Scratch interage de forma simplificada com os alunos que ainda estão no Ensino Fundamental, auxiliandoos no desenvolvimento do pensamento computacional e despertando neles o interesse pela Computação.

\footnotetext{
${ }^{1} \mathrm{O}$ sistema LEGO é um brinquedo cujo conceito se baseia em partes que se encaixam permitindo muitas combinações. Para mais informações acesse http://www. lego. com
} 
A linguagem Scratch permite que o aluno visualize o ambiente de forma acessível através uma interface que facilita a montagem dos projetos por meio de blocos que são arrastados para a tela e se encaixam como um brinquedo, conforme ilustrado na Figura 1. Deste modo, o ambiente permite a criação de jogos, histórias e animações interativas, explorando, assim, a imaginação e a intuição do aluno. Isto é devido ao fato de que todo o processo de desenvolvimento acontece por meio de blocos, tornando a construção do algoritmo clara e ao mesmo tempo visível. Neste mesmo ambiente acontece a visualização do que é programado, facilitando a compreensão da execução do algoritmo.

Outros trabalhos na literatura identificaram evidências de que o Scratch pode ser usado para ensinar e incentivar o interesse pela programação de computadores, tais como [Alencar et al. 2014, Dias e Serrão 2014]. Neste trabalho, procuramos contribuir com mais evidências que corroboram com esses resultados.

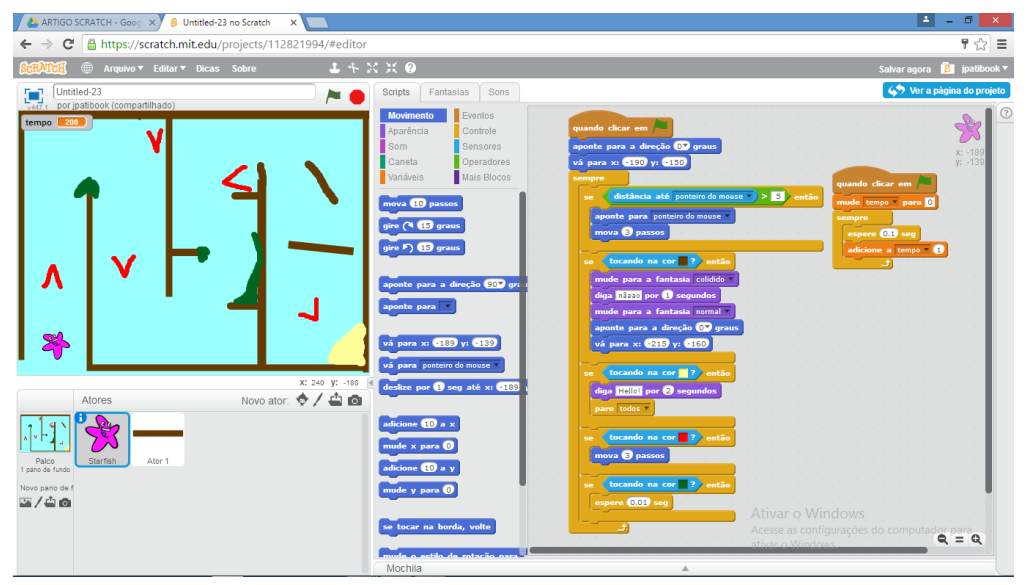

Figura 1. Interface gráfica do Scratch.

\section{Metodologia}

Este trabalho foi desenvolvido por meio de um clube de programação, baseado no Code $\mathrm{Club}^{2}$, uma rede mundial de atividades extra-curriculares gratuitas, completamente gerenciada por voluntários, com o objetivo de ensinar programação de computadores às crianças. Com base nesta iniciativa, foi criado um clube de programação em parceria com um Colégio Estadual do município de Palotina-PR. Os encontros do clube são semanais e possuem duração aproximada de $1 \mathrm{~h}$ e $30 \mathrm{~min}$, por um período de 3 meses, e já participaram alunos dos $6^{\circ}, 7^{\circ}$ e $8^{\circ}$ Anos do Ensino Fundamental. Os encontros foram direcionados e ministrados por dois alunos do curso de Licenciatura em Computação da UFPR e um professor-orientador. A primeira turma teve, ao todo, 16 alunos inscritos e uma professora de Matemática. Tanto a direção do colégio quanto a equipe pedagógica forneceram o apoio necessário para a divulgação do projeto e o incentivo para a participação dos alunos.

A metodologia utilizada neste trabalho baseia-se no desenvolvimento de pequenos projetos por parte dos estudantes, visando proporcionar uma maior interação com a linguagem de programação de forma simples, intuitiva e criativa. Durante as aulas, os alunos aprendem conteúdo prático e teórico com aplicação em jogos, histórias e animações

\footnotetext{
${ }^{2}$ http://codeclubbrasil.org/
} 
interativas. Deste modo, os alunos têm a possibilidade de construir o seu conhecimento computacional e não somente reproduzir processos mecânicos de aprendizagem. Os alunos também são estimulados a partilhar de suas ideias e projetos de modo interativo com os demais colegas para que se sintam motivados a frequentar e participar dos encontros semanais.

Além do clube de programação, também realizamos eventualmente oficinas em dias específicos, tais como o Scratch Day, que ocorre simultaneamente em várias localidades no mundo todo. Acreditamos que a consciência de estarem participando de algo que ocorre globalmente estimula ainda mais o interesse dos alunos em participarem das oficinas e do clube. Em 2015, aplicamos um questionário online facultativo a alunos que participaram de uma dessas oficinas, que ocorreu durante a $5^{\text {a }}$ FECITEC (Feira de Ciência e Tecnologia de Palotina). Os resultados são apresentados na Seção 4.

\section{Resultados e Discussão}

Em uma oficina de programação realizada em 2015 foi aplicado um questionário buscando levantar a avaliação e a opinião dos alunos em relação à oficina. No total, 17 alunos responderam. $70 \%$ dos alunos responderam que a oficina ajudou muito em seu entendimento sobre programação, enquanto $24 \%$ acharam que o curso contribuiu apenas de modo razoável. $94 \%$ responderam que pretendiam continuar a utilizar a linguagem Scratch em casa, e 100\% dos alunos responderam que teriam interesse em participar de outras oficinas. Isto é um indicativo de que o Scratch, de fato, despertou interesse nos alunos. Dentre as sugestões abertas, houve comentários de que poderia haver mais oficinas, com maior frequência, e que as oficinas poderiam ter carga horária maior. Estes resultados indicam que, de fato, as oficinas com Scratch despertaram nos alunos o interesse por programação. Além disso, este é mais um dos motivos para termos prosseguido com a realização de oficinas e a criação de um clube de programação.

Algumas imagens do clube e das oficinas de programação realizadas são apresentadas na Figura 2.
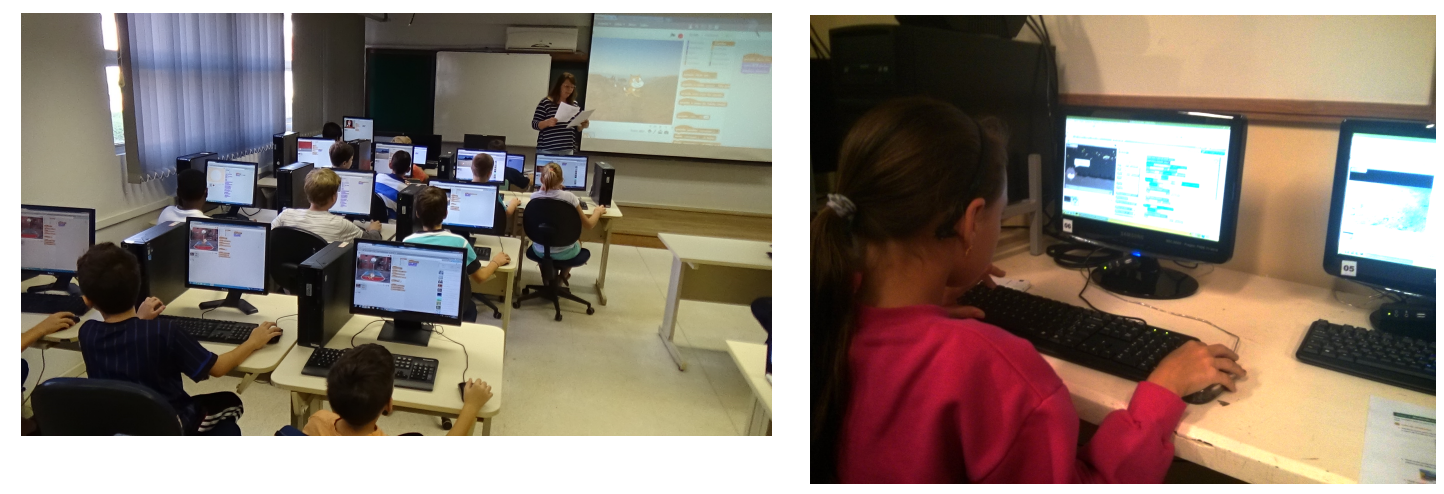

Figura 2. Fotos do Scratch Day e do clube de programação

\section{Conclusão}

Conclui-se através deste projeto que o uso da linguagem e ambiente Scratch é uma ferramenta viável para introduzir, a alunos do Ensino Fundamental, o pensamento computacional e a aprendizagem de conceitos computacionais que exercitam o raciocínio lógico e matemático. 
V Congresso Brasileiro de Informática na Educação (CBIE 2016)

Anais do XXII Workshop de Informática na Escola (WIE 2016)

Mesmo tendo pouco tempo de existência, o projeto contou com a participação de alunos que demonstraram interesse nas aulas e na maneira com que a programação foi abordada.

A construção de algoritmos e a apresentação de sua execução na interface gráfica do Scratch é algo que entusiasmou e motivou os alunos para a participação, pois a programação desenvolvida na sala de aula torna-se divertida e compreensível. Os conceitos de operadores, estruturas de decisão, de repetição e variáveis são aprendidos de forma simples pois remetem aos encaixes de blocos.

Contudo a viabilidade de criarem diversos jogos e animações e continuarem desenvolvendo em casa estimula ainda mais o interesse, assim como a possibilidade de compartilhar seus projetos e interagir com colegas, promovendo-se uma troca de aprendizagem.

\section{Referências}

Papert, S. (1972). Teaching children to be mathematicians versus teaching about mathematics. International Journal of Mathematical Education in Science and Technology, 3(3):249-262.

Valente, J. A. (1999). O computador na sociedade do conhecimento. UNICAMP/NIED, São Paulo.

Júnior, J. C. R. P., Rapkiewicz, C. E., Delgado, C., e Xexeo, J. A. M. (2005). Ensino de algoritmos e programação: Uma experiência no nível médio. In XIII Workshop de Educação em Computação (WEI'2005), pages 2351-2362, São Leopoldo, RS.

Wing, J. M. (2006). Computational thinking. Communications of the ACM, 49(3):33-35.

Castro, T., Fuks, H., Spósito, M. A. F., e de Castro Jr, A. N. (2008). Análise de um Estudo de Caso para Aprendizagem de Programação em Grupo. Revista Iberoamericana de Tecnologias del Aprendizaje, 4(2):155-160.

Rebouças, A. D. D. S., Marques, D. L., Costa, L. F. S., e Silva, M. A. A. (2010). Aprendendo a Ensinar Programação Combinando Jogos e Python. In Anais do Simpósio Brasileiro de Informática na Educação, volume 1, pages 1-10.

Maloney, J., Resnick, M., Rusk, N., Silverman, B., e Eastmond, E. (2010). The scratch programming language and environment. Trans. Comput. Educ., 10(4):16:1-16:15.

Dias, K. L. e Serrão, M. d. L. (2014). A linguagem scratch no ensino de programação: Um relato de experiência com alunos iniciantes do curso de licenciatura em computação. In Anais do Workshop de Informática na Escola, Brasília-DF.

Alencar, G. A., Freitas, A. K., e Danielle, J. (2014). Utilizando o scratch nas aulas de lógica de programação do proeja: Um relato de experiência. In Nuevas Ideas en Informática Educativa TISE 2014, pages 542-545, Fortaleza, CE. 